\title{
Effect of Diet and Nutrient on Cell Signaling: Is the Tissue the Main Issue, Proposes Dr. Wilson?
}

\author{
R.B. Singh ${ }^{1, *}$, Eri Toda ${ }^{2}$, Takahashi Toru ${ }^{3}$, Miki Tokunaga ${ }^{4}$, Kuniaki Otsuka ${ }^{5}$, Lekh Juneja ${ }^{6}$, Fabien \\ De Meester ${ }^{1}$, Agnieszka Wilczynska $^{1}$ and Douglas Wilson ${ }^{7}$
}

\author{
${ }^{1}$ The Tsim Tsoum Institute, Krakow, Poland \\ ${ }^{2}$ Department of Medicine, Tokai University Hachioji Hospital, Tokyo, Japan \\ ${ }^{3}$ Department of Nutrition and Health Science, Graduate School of Human Environment Science, Fukuoka Women's \\ University, Japan \\ ${ }^{4}$ Department of Food and Health Science, Fukuoka Women's University, Japan \\ ${ }^{5}$ Tokyo Women's Medical University, Medical Center East, Tokyo, Japan \\ ${ }^{6}$ Taiyo Kagaku Co., Ltd. Yokkaichi, Japan \\ ${ }^{7}$ School Medicine, Pharmacy and Health, Durham University, UK
}

\begin{abstract}
Western diet is characterized with energy dense, refined, ready prepared foods with a high glycemic index (e.g. refined starches; bread, biscuits, candies, cornflakes, pizza, potato chips, cola drinks and sugar) and unhealthy lipids (e.g. trans fats, saturated fat, w-6 rich oils) poor in w-3 fatty acids, phytochemicals and fiber that are abundant in the Mediterranean type of diet. Western type of diets are known to predispose inflammation and increase in free fatty acids causing endothelial cell and beta cell dysfunction leading to the epidemic of cardiovascular diseases (CVDs). The cell signaling and the changes in cell membrane properties of the tissues induced by dietary lipids may have important consequences on the development of obesity, atherosclerosis and hypertension. The structural properties and function of cell membrane proteins appear to be modified in hypertensive humans and animal models of hypertension and atherosclerosis. Diet induced alterations in membrane lipid composition of hypertensive subjects have been associated with alterations in the transmembrane fluxes of $\mathrm{Na}^{+}$and $\mathrm{K}^{+}$, including $\mathrm{Na}^{+}-\mathrm{Li}^{+}$countertransport, which is a marker of essential hypertension, and in cell signaling proteins that participate in the control of blood pressure. It has been demonstrated that dietary lipids have an effect on membrane lipid composition and cell signaling proteins. Since changes in the dietary lipid composition yield to variations in the biophysical properties of the plasma membrane, it is likely that cellular functional changes could result from alterations in the structure of the lipid membrane properties under influence of the diet. Thus, the changes in membrane properties induced by dietary lipids may have important consequences on blood pressure regulation. The Mediterranean diet has been associated with changes in membrane structure and function. Consumption of olive oil-rich diets increases the concentration of oleic acid in plasma membrane lipids of different rat and human cells, with beneficial consequences on membrane functionality. In contrast, very little is currently known regarding the effects of nuts, another key ingredient of such diets, on membrane lipid composition and structure. CVD, diabetes mellitus and obesity, that are associated with increased production of thromboxane A2(TXA2), leukotrienes, prostacyclin, interleukins-1 and 6, tumor necrosis factor-alpha and C-reactive proteins in the tissues, is the major issue. Increased dietary intake of w- 6 fatty acids is known to enhance all these biomarkers as well as atherogenicity of cholesterol in the tissues which have adverse proinflammatory effects resulting in CAD. Mediterranean diet rich in fruits, vegetables, nuts, mustard oil, and olive oil characterized with low w-6/w-3 ratio in the diet, can modulate inflammation and endothelial dysfunction of the tissues and may be protective against risk of coronary artery disease (CAD) and all-cause mortality. Inflammation appears to be an important unifying hypothesis, because in the absence of inflammation in the tissues, total cholesterol and other lipids may have neutral effects in the arterial tissues and myocardium. Therefore, it seems that endothelial dysfunction and inflammation in the tissue is the main issue for treatment.
\end{abstract}

Keywords: Paleolithic diet, lipids, oxidative stress, Mediterranean diet, nutrition, cardiovascular disease, w-6/w3 fatty acids ratio.

*Address correspondence to this author at the Tsim Tsoum Institute, Krakow, Poland; Tel/Fax: 00915912417437; E-mail rbs@tsimtsoum.net

\section{INTRODUCTION}

We are indebted to Dr. Douglas Wilson due to his vision for prevention of illness from cell to society. Atherosclerosis 
and hypertension are complex diseases resulting from an interaction between body tissues and environmental risk factors such as the Western diet, tobacco consumption, lack of exercise, stress, disruption of sleep and geomagnetic forces, underlying a favourable genetic profile [1-3]. Apart from these primary risk factors, secondary risk factors, obesity, hypertriglyceridemia hypercholesterolemia, hypertension and diabetes mellitus can further enhance the mechanism of endothelial and smooth muscle cell dysfunction resulting in atherosclerosis and hypertension [2, 3]. In addition, it has become clear that innate and adaptive immune systems are involved in the initiation and progression of atherogenesis and cardiovascular diseases (CVDs) [3-5]. Development of hypertension has been linked to chronic low-grade inflammation leading to smooth muscle cell dysfunction. However, it is not known whether this connection is mediated by features of the metabolic syndrome, dietary factors or smoking, or their changes, which themselves have been linked to inflammation [6-8].

In the 19th century, the pathologists C. von Rokitansky and Rudolf Virchow were the first to describe cellular inflammatory changes in the atherosclerotic vessel walls apart from accumulation of cholesterol. Virchow considered inflammation to have primary role, however, von Rokitansky considered these changes secondary in nature, in response to fibrin-induced alterations. The increase in the tissue cholesterol including blood cholesterol appears to be due to adaptive response of the body organs particularly liver, which generates excess of cholesterol to fight the inflammation and fluidity of endothelial cell membranes due to its potential antioxidant activity. A significant number of genetic variants associated with the various phenotypes of atherosclerosis or its risk factors have been identified. Each, taken individually, only exerts a modest influence, but as a group, they may have a significant role. However, as yet these are not precisely quantified in the aetiology of atherosclerosis and hypertension. The individual response to various therapies including Mediterranean diet, physical activity and drugs prescribed in atherosclerosis and hypertension can also be significantly influenced by genetic factors. In the near future, genetics, nutriogenetics and pharmacogenetics will represent major determinants of our approach to the prevention and individualized treatment of CVDs and its complications. Apart from w-6/w-3 fatty acid ratio and cholesterol, green tea, catechin, grape juice, etc. may also influence cell function and dysfunction [9-17]. A dietary deficiency of these nutrients may increase the susceptibility of the tissue cholesterol to oxidation resulting in an accumulation of oxidized cholesterol which is more attractive to macrophages in the mechanism of atherothrombosis. Maddaford et al (1999) has proposed a model of low-flow ischemia and reperfusion in single, beating adult cardiomyocytes, which, may be used to study the effects of antioxidant nutrients on the cardiomyocyte [15]. Ischemia and reperfusion in the myocardium initiates metabolic and ionic perturbations, mostly as a result of oxidative stress, ultimately leading to cell demise and tissue necrosis. Cardiac cells appear to have limited ability to proliferate. Therefore, reducing cell death during ischemiareperfusion is of great importance in preventing the irreversible injury. Antioxidant polyphenols, especially flavonoids are well acknowledged for their antioxidant and protec- tive effects in circumstances of oxidative stress [9-14]. They have also been recognized to interact with cell death-survival signaling pathways which depending on the dose may promote or inhibit apoptosis, exhibiting chemopreventive or cytoprotective effects, respectively. In the present review, we discuss the role of diet and nutrients in the pathogenesis and prevention of tissue alterations in CVDs.

\section{DIET, DEVELOPMENT AND CARDIOVASCULAR DISEASES OF THE TISSUES}

The diets of Homo sapiens were characterized by natural foods; fruits, vegetables, green leaves, seeds, eggs, fish, meat from running animals and honey during the Paleolithic period $[18,19]$. These foods were also available to preagricultural humans which shaped modern human's genetic nutritional requirement [11-15]. Cereal grains (refined), and vegetable oils that are rich in w- 6 fatty acids and trans fats and low in amino acids are relatively recent additions to the human dietary patterns that represent dramatic departure from those foods and nutrients to which we are adapted [20, 22]. Early man also had enormous physical activity without any mental stress. The role of fatty acids, essential and nonessential amino acids, antioxidants and vitamins in the prevention and pathogenesis of CVDs, type 2 diabetes and insulin resistance are well known [23-27]. There is evidence that the Mediterranean diet which has similarity with Paleolithic diet can also influence brain function related to gut-liverbrain-heart axis indicating its influence on mind-body connection [28-30].

Humans appear to live in a nutritional environment which completely differs from that for which our genetic constitution was selected [19-24]. This is because, food consumption patterns have changed significantly during the last 100-160 years, causing increased intake of saturated fatty acids (SFA), trans fat, refined carbohydrates and linoleic acid, and decreased w-3 fatty acids, from grain-fed cattle, tamed at farm houses, rather than meat from running animals. Apart from hyperlipidemia and hyperglycemia, oxidative stress and inflammation appear to be important mechanisms in the pathogenesis and prevention of diet-related NCDs [31-34]. Adverse effects of Tamasic foods characteristics of the Western diet were also proposed by Indian ancient physicians; Charak and Sushruta in $600 \mathrm{BCE}$ as well as by Confucius in China (500BCE) and by Greek physician Hippocrates (500BCE) [35].

The food and nutrient intake among hunter-gatherers and among Western and Asian populations show marked reductions in the consumption of w-3 fatty acids, vitamins, antioxidants, and amino acids and significant increases in the intakes of carbohydrates, (mainly refined) fat (saturated, trans fat, and linoleic acid), and salt compared to Paleolithic period (Tables 1-5). The protein or amino acid intake was 2.5 fold greater (33 vs. $13 \%$ ) in the Paleolithic diet compared to modern diet (Table 3). Approximately 10,000 years ago, prior to the Agricultural Revolution, our diet was based on an enormous variety of wild plants. However, today about $17 \%$ of plant species provide $90 \%$ of the world's food supply which is mainly contributed by grains. Wheat, corn and rice account for three quartersof the world's grain production on which humans are dependent for food supply. Grains are 
Table 1. Food and Nutrient Intake Among Hunter-gatherer and Western Populations

\begin{tabular}{|l|l|l|l|}
\hline Food and Nutrient & Hunter-Gatherer & Western Population & Asians \\
\hline \hline Energy density & Low & High & Low \\
Protein & High & Low-moderate & Low \\
Animal & High & Low -moderate & Low \\
Vegetable & Very low & Low - moderate & Low \\
Carbohydrate & Low-moderate(slowly ab- & Moderate-rapidly absorbed & High \\
& sorbed) & & Low \\
Fiber & High (>30g) & Low (<15g) \\
Fat & Low & High & Low \\
Animal & Low & High & High \\
Vegetable & Very low & Low $(0.2 \mathrm{~g} /$ day) & $0.5-0.85 \mathrm{~g}$ \\
Total w-3 & High(2.3g/day) & High 15-20 & $25-50$ \\
Ratio w-6:w-3 & Low 2.4 & low & moderate \\
Vitamins and minerals & High & &
\end{tabular}

Modified from Eaton et al. [19] and Singh et al. [46] references.

high in w-6 fatty acids and carbohydrates and low in w-3 fatty acids and antioxidants compared to leafy green vegetables. Eaton and co-workers $[19,20]$ have estimated higher intakes for protein, calcium, potassium and ascorbic acid and a lower intake of sodium in the diet of late Paleolithic period than the current diets in the developed and developing countries. Green leafy vegetables are also rich sources of antioxidants, magnesium, w-3 fatty acids and carotenoids which appear to be high in the Paleolithic diet. The proteins which were from both animal (running animals and eggs) and plant sources (green leaves and seeds), should have been composed of both essential and non-essential amino acids (Tables 1 and 3).

There has been an enormous increase in w- 6 fatty acid (about $30 \mathrm{~g} /$ day) in the diet due to the production of oils from vegetable seeds such as corn, sunflower, saiflower, soybean and cotton. Increased intake of meat has resulted in greater intake of arachidonic acid $(0.2-1.0 \mathrm{mg} /$ day $)$, whereas the consumption of alpha-linolenic acid (ALA) has decreased (about $0.55 \mathrm{~g} / \mathrm{day}$ ) and the amounts of eicosapentaenoic acid (EPA) and docosahexaenoic acid (DHA) are 48 and $72 \mathrm{mg} /$ day respectively (Tables 4-6). A relative and absolute decrease in w-3 fatty acids has led to an imbalance and increase in the ratio of w-6/w- 3 fatty acids in a range of 20 to 50 in the Western countries, South Asia and other developing countries, consuming vegetable seed oils [36-40]. Saturated fatty acids (SFA) and trans fatty acids (TFA) elevate, PUFA decrease, and mono-unsaturated fatty acids (MUFAs) have beneficial effects on total and low density lipoprotein cholesterol (LDL) as well as on high density lipoprotein (HDL) cholesterol. Omega-6 PUFA and TFA also decrease HDL cholesterol, and increase insulin resistance, free radical stress and inflammation, which may enhance atherosclerosis [36-38]. Increased intake of total fat and SF in the pathogene
Table 2. Estimated Fatty Acid Consumption in the Late Paleolithic Period

\begin{tabular}{|c|c|}
\hline Sources & $\begin{array}{c}\text { Fatty Acids(g/day) en } \\
\text { 35.65/day }\end{array}$ \\
\hline \multicolumn{2}{|l|}{ Plants } \\
\hline Linoleic acid & 4.28 \\
\hline Alpha-linoleic acid & 11.40 \\
\hline \multicolumn{2}{|l|}{ Animal } \\
\hline Linoleic acids & 4.56 \\
\hline Alpha-linolenic acid & 1.21 \\
\hline \multicolumn{2}{|l|}{ Total } \\
\hline Linoleic acid & 8.84 \\
\hline Alpha linolenic acid & 12.60 \\
\hline \multicolumn{2}{|l|}{ Animal } \\
\hline Arachidonic acid(w-6) (AA) & 1.81 \\
\hline \multicolumn{2}{|l|}{ Long chain $w-3$ fatty acids } \\
\hline Eicosapentaenoic acid(w-3)(EPA) & 0.39 \\
\hline Docosatetraenoic acid(w-6) (DTA) & 0.12 \\
\hline Docosapentaenoic acid(w-3)(DPA) & 0.42 \\
\hline Docosahexaenoic acid(w-3)(DHA) & 0.27 \\
\hline Total long chain $w-3$ fatty acids & 1.20 \\
\hline Ratios of w-6/w-3 & 0.70 \\
\hline $\begin{array}{l}\text { Linoleic acid/alpha linolenic acid+ } \\
\text { AA+DTA/EPA+DPA+DHA }\end{array}$ & 1.79 \\
\hline Total w- $6 / w-3$ & 0.77 \\
\hline
\end{tabular}


Table 3. Nutrient Composition in the Late Paleolithic and Current Recommendations

\begin{tabular}{|l|l|l|}
\hline \multicolumn{1}{|c|}{ Nutrient per day } & \multicolumn{1}{|c|}{ Late Paleolithic } & \multicolumn{1}{c|}{ Current Recommendation } \\
\hline \hline Total dietary energy\% & & 12 \\
Protein & 33 & 58 \\
Carbohydrate & 46 & 30 \\
Fat & 21 & moderate alcohol \\
Alcohol & -0 & 1.00 \\
P/S ratio & 1.41 & 300 \\
Cholesterol, mg & 520 & $30-60$ \\
Fiber, g & $100-150$ & $1100-3300$ \\
Sodium, mg & 690 & $800-1600$ \\
Calcium, mg & $1500-2000$ & 60 \\
Ascorbic acid, mg & 440 & \\
\hline
\end{tabular}

Modified from Eaton et al. [18] their references 1, 2 and Singh et al. [46], their references [1,2,46].

sis of CAD has been established in the Seven Countries Study [41]. The adverse effects of TFA, SFA and w-6 fatty acids and refined carbohydrates, causing obesity and insulin resistance resulting in $\mathrm{CAD}$, have been reviewed by several researchers [20, 22, 28]. Decreased intake of MUFA [42-45], w-3 fatty acids [20, 46-48], fiber and phytochemicals, may enhance the metabolic syndrome, leading to CVDs [23, 49$51,52]$.

In a randomized crossover design, 50 men consumed controlled diets for 5 wks that provided $15 \%$ of energy from protein, $39 \%$ of energy from fat, and $46 \%$ of energy from carbohydrate [8]. Eight percent of fat or fatty acids was replaced across diets with the following: cholesterol, oleic acid, trans fatty acids (TFAs), stearic acid (STE), TFA+STE (4\% of energy each), and 12:0-16:0 saturated fatty acids (LMP). The study reported higher fibrinogen concentrations after consumption of the diet enriched in stearic acid than after consumption of the carbohydrate diet. C-reactive protein concentrations were higher after consumption of the TFA diet than after consumption of the carbohydrate diet, but were not significantly different after consumption of the TFA and TFA+STE diets than after consumption of the LMP diet. Interleukin 6 concentrations were lower after consumption of the oleic acid diet than after consumption of the LMP, TFA, and STE diets. E-selectin concentrations were higher after consumption of the TFA diet than after consumption of the carbohydrate diet. Consumption of the TFA but not the TFA+STE diet resulted in higher E-selectin concentrations than did the LMP diet.

\section{THE TISSUE IS THE ISSUE AND THE SIGNALING MOLECULES.}

Rudolph Carl Virchow (13 October 1821 - 5 September 1902) was a German doctor, anthropologist, pathologist, prehistorian, biologist and politician, known for his advancement of public health and pathology. He is considered one of the founders of social medicine and cell biology. He advised the students to examine the cells microscopically and treat microscopically. As a young physician, Rudolf Virchow held the then-radical belief that disease originates in cells, not in organs, or entire organisms. It is now well accepted that cells are the major building blocks of tissues which appears to be the main issue in the development of health or a disease.

Thus German scientists were the first to report the biological composition of atheroma in the arterial tissue indicating the presence of cholesterol and inflammatory cells. However, in modern period, researchers from the Western world gave greater attention to atheroma cholesterol and blood cholesterol and ignored the inflammatory cells in the pathogenesis of atherosclerosis. CVD, diabetes mellitus, and obesity, are associated with increased production of thromboxane A2(TXA2), leukotrienes, prostacyclin, interleukins-1 and 6, tumor necrosis factor-alpha and C-reactive proteins in the tissues which are cell signaling molecules. Increased dietary intake of w- 6 fatty acids is known to enhance all these biomarkers as well as atherogenicity of cholesterol in the tissues

Table 4. Ethnic Differences in Fatty Acid Levels in Thrombocytes Phospholipids and Percentage of All Deaths from Cardiovascular Disease

\begin{tabular}{|l|l|l|l|}
\hline & \multicolumn{1}{|c|}{ Europe and USA \% } & Japan \% & Greenland Eskimos \% \\
\hline \hline Arachidonic acid(20:4w6) & 26 & 21 & 8.3 \\
Eicosapentaenoic acid(20:5w-3) & 0.5 & 1.6 & 8.0 \\
Ratio of w-6/w-3 & & 12 & 1 \\
Mortality from cardiovascular disease & 50 & 12 & 7 \\
& 45 & 12 & \\
\hline
\end{tabular}

Modified from Singh et al [46], their references [1,2,44]. 
Table 5. Fatty Acids ratio in the Diets

\begin{tabular}{|l|l|l|}
\hline \multicolumn{1}{|c|}{ Subjects } & \multicolumn{1}{|c|}{ w-6/w-3 } & \\
\hline \hline Paleolithic & 0.79 & Estimated \\
Greece prior to 1960 & $1.00-2.00$ & Current 7.10 \\
Japan & 4.00 & Early $1-2$ \\
India, rural & $5-6.1$ & Prior to 1960, 3-4 \\
India urban & $38-50$ & Prior to 1960, 5-10 \\
UK & 15.00 & Prior to 1960,10.00 \\
Northern Europe & 15.00 & Prior to 1960,10.00 \\
USA & 16.74 & Prior to 1950 7-8 \\
Eastern Europe & $20-25$ & Estimated \\
Indian hunter-gatherers & $1.00-2.00$ & Estimated \\
\hline
\end{tabular}

which have adverse pro-inflammatory effects resulting in CAD. However, increased consumption of w-3 fatty acids has been found to suppress all these biomarkers in the tissues resulting in a decline in $\mathrm{CAD}$ and other chronic diseases. Linolenic acid (w-3) and linoleic acid (w-6) are polyunsaturated fatty acids which contain long carbon chains of 18 carbons each that are not present in the structure of oleic acid and steric acid. Both w-3 and w- 6 fatty acids are called essential fatty acids which have to be obtained from the diet. Some of these essential fatty acids are converted into 20 carbon fatty acid containing 4 carbon-carbon double bonds. Another w-6 fatty acid, arachidonic acid, is an important starting material for 3 different types of signaling molecules. Similarly, linolenic acid can metabolize into DHA and EPA long chain w-3 fatty acids in presence of delta- 6 desaturase enzyme. Prostaglandins, which are released from prostate, contain double bonds located in the same position as the double bonds in the w-3 and w- 6 fatty acids which suggest that these fatty acids may be the precursor of these signaling molecules.

Apart from prostaglandins, thromboxanes and leukotrienes are also produced by these fatty acids, mainly via w-6 fatty acids and they are called eicosanoids [53-55]. All the cells in our body except red blood cells produce one or more of these signaling molecules. Thromboxanes produced in platelets constrict blood vessels and promote platelet aggregation. Leukotrienes attract immune cells such as neutrophils to site of inflammation, constrict bronchioles in lungs and enhance capillary permeability [55]. Arachidonic acid and w-3 fatty acids stored as components of phospholipids on the plasma membrane of cells are cleaved by the specific phospholipase enzyme away from the phospholipid allowing the cyclooxygenase (COX) enzyme to start the conversion process. These molecules bind to cell surface proteins of the seven-helix G -proteins coupled receptors which in turn activate the cyclic AMP pathway or the inositol phosphatecalcium pathway which can produce immediate as well as long term alteration in cell functions. The same 20 carbon structural element was found in the tetrahydrocannabinol which was identified as anandamide as the active signaling molecule in the brain [56]. Food intake can be regulated by PUFA as it can modulate the endogenous lipids N-acetyl- ethanolamine (anandamide) and 2-acyl-glycerols which are the ligands of cannabinoid receptors that are important for food intake, wellness and satiety. The term anandamide was coined by the Sanskrit root ananda meaning bliss [56]. This molecule was also built from the 20 carbon molecule of w-3 fatty acids and arachidonic acid. The amount of various fatty acids; w-6, trans fat, saturated fat and w-3 fat in our diet could increase or decrease the synthesis of prostaglandins, thromboxanes and leukotrienes in our body which may alter the effects of these signals on their normal target cells. The reactions produced by these signaling molecules may be altered by certain drugs like aspirin, clopidogral, nutrients like coenzyme Q10, vitamin E, resveratrol and functional foods like tomato and grapes. How our diet influences these pathways appears to be interesting, because w-3 fatty acids rich in Mediterranean diet, are known to inhibit and w- 6 fatty acids rich in the Western diets, enhance these pathways resulting in inflammation in the tissues responsible for CVDs. Arginine can also act like an anti-inflammatory agent by inhibiting C-reactive protein [57].

There is an experimental study which showed that increased availability of w- 6 fatty acid in the tissues enhances the formation of w-3 fatty acids by the animals due to extraordinary capability of the animals to fight the adverse effects of w-6 fatty acids [50]. There is evidence that flavonoids can protect against cardiac ischemia-reperfusion injury, the relative effectiveness of different flavonoids and the mechanisms involved are unclear [16]. A study compared protection by different flavonoids using rat embryonic ventricular H9c2 cells subjected to simulated ischemiareperfusion (IR) and to tert-butyl hydroperoxide (t-buOOH). Characterization of the IR model showed the relative contributions of glucose, serum, and oxygen deprivation to cell death. With long-term (2-3 day) pretreatment before IR the best protection was given by catechin, epigallocatechin gallate, proanthocyanidins, and ascorbate, which protected at all doses investigated. Quercetin protected (34\%) at $5 \mu \mathrm{M}$ but was cytotoxic at higher doses. Cyanidin protected mildly $(10-15 \%)$ at 5 and $20 \mu \mathrm{M}$, while delphinidin had no effect at $5 \mu \mathrm{M}$ and was cytotoxic at higher doses. Comparing longterm and acute protection by catechin, a higher concentration was needed for benefit with acute $(1 \mathrm{~h})$ pretreatment. Only 
quercetin significantly protected with 3-day pretreatment, while with short-term $(1 \mathrm{~h})$ pretreatment protection was best with quercetin and epigallocatechin gallate. The results suggest catechins to be especially useful as IR preconditioning agents, while quercetin and epigallocatechin gallate may be the most protective acutely in situations of high oxidative stress. Grape seed polyphenols can also protect cardiac cells from apoptosis via induction of endogenous antioxidant enzymes [12]. Similarly green tea poly phenols; epigallocatechin-3-gallate may influence cell signaling pathways in neuroprotective activity [11]. Dietary green tea extract is known to increase phase 2 enzyme activities in protecting against myocardial ischemia-reperfusion [13]. Epigallocatechin-3gallate (EGCG), a green tea polyphenol, also improves endothelial function and insulin sensitivity, reduces blood pressure, and protects against myocardial I/R injury in SHR [14].

Dietary flaxseed has been shown to have potent antiatherogenic effects in rabbits [17]. This study shows the antiatherogenic capacity of flaxseed in an animal model that more closely represents the human atherosclerotic condition. LDL receptor-deficient mouse (LDLrKO) were administered a regular diet, a 10\% flaxseed-supplemented diet (FX), or an atherogenic diet containing $2 \%$ cholesterol alone $(\mathrm{CH})$ or supplemented with 10\% flaxseed (CF), 5\% flaxseed (CF5), $1 \%$ flaxseed (CF1), or 5\% coconut oil (CS) for $24 \mathrm{wks}$. LDLrKO mice fed a cholesterol-supplemented diet exhibited a rise in plasma cholesterol without a change in triglycerides and an increase in atherosclerotic plaque formation [17]. The CS mice exhibited elevated levels of plasma cholesterol, triglycerides, and saturated fatty acids and an increase in plaque development. Supplementation of the cholesterolenriched diet with 10\% (wt/wt) ground flaxseed lowered plasma cholesterol and saturated fatty acids, increased plasma ALA, and inhibited plaque formation in the aorta and aortic sinus compared with mice fed a diet supplemented with only dietary cholesterol. The expression of proliferating cell nuclear antigen (PCNA) and the inflammatory markers IL-6, Mac-3, and VCAM-1 was increased in aortic tissue from $\mathrm{CH}$ and $\mathrm{CS}$ mice. This expression was significantly reduced or normalized when flaxseed was included in the diet. The results demonstrate that dietary flaxseed can inhibit atherosclerosis in the LDLrKO mouse through a reduction of circulating cholesterol levels and, at a cellular level, via antiproliferative and anti-inflammatory actions.

Despite use of hemp seed, in our diet for hundreds of years, there is surprisingly little research published on its physiological effects [10]. Hemp seed has an excellent content of omega- 3 and omega- 6 fatty acids. These compounds have beneficial effects on our cardiovascular health provided w-6 fatty acid is not too much. This article reviews the latest developments in this rapidly emerging research field with a focus on the cardiac and vascular effects of dietary hempseed. It is very rich in essential fatty acids (EFAs) and other polyunsaturated fatty acids (PUFAs). It has almost as much protein as soybean and is also rich in vitamin $\mathrm{E}$ and minerals such as phosphorus, potassium, sodium, magnesium, sulfur, calcium, iron, and zinc. Hempseed oil contains all of the essential amino acids and also contains surprisingly high levels of the amino acid arginine, a metabolic precursor for the production of nitric oxide (NO), a molecule now recognized as a pivotal signaling messenger in the cardiovascular system that participates in the control of hemostasis, fibrinolysis, platelet and leukocyte interactions with the arterial wall, regulation of vascular tone, proliferation of vascular smooth muscle cells, and homeostasis of blood pressure.

In a further study that included 13401 participants, 25 years and older from the Third National Health Nutrition and Examination Survey, an independent relationship was shown between the dietary intake of L-arginine and levels of CReactive protein, a marker strongly correlated with the risk of cardiovascular disease (CVD) [18].

\section{MEDITERRANEAN DIET AND CELL SIGNALING}

The changes in cell membrane properties of the tissues induced by dietary lipids may have important consequences on the development of atherosclerosis, hypertension and blood pressure regulation $[58,59]$. The mechanisms and effects of the Mediterranean diet on the molecular and structural bases underlying the physiological process are largely unknown. The structural properties and function of cell membrane proteins appear to be modified in hypertensive humans and animal models of hypertension. Diet induced alterations in membrane lipid composition of hypertensive subjects have been associated with alterations in the transmembrane fluxes of $\mathrm{Na}^{+}$and $\mathrm{K}^{+}$, including $\mathrm{Na}^{+}-\mathrm{Li}^{+}$countertransport, which is a marker of essential hypertension, and in cell signaling proteins that participate in the control of blood pressure. Prades et al [58] have demonstrated that dietary lipids have an effect on membrane lipid composition and cell signaling proteins. Since changes in the dietary lipid composition yield to variations in the biophysical properties of the plasma membrane, it is likely that cellular functional changes could result from alterations in the structure of the lipid membrane properties influenced by the diet. Thus, the changes in membrane properties induced by dietary lipids may have important consequences on blood pressure regulation.The Mediterranean diet has been associated with changes in membrane structure and function. Consumption of olive oil-rich diets increases the concentration of oleic acid in plasma membrane lipids of different rat and human cells, with beneficial consequences on membrane functionality. In contrast, very little is currently known regarding the effects of nuts, another key ingredient of such diets, on membrane lipid composition and structure.

The Mediterranean-style diet is characterized by a high consumption of virgin olive oil and walnuts, which are rich natural sources of oleic (18:1;n-9) and $\alpha$-linolenic $(18: 3$; n3 ) acids, respectively. The Prevencion con Dieta Mediterranean (PREDIMED) Study is a large-scale, randomized trial aimed at assessing the effects of a Mediterranean diet on primary prevention of cardiovascular disease in patients at high risk for CAD [59]. The results of the 3-month intervention on the first 772 patients entering the study showed that, compared with a low-fat diet, the Mediterranean diet rich in virgin olive oil or nuts reduced systolic blood pressure and serum total cholesterol and triglyceride concentrations and increased serum HDL concentration.

In a structured sub-study, the authors assessed the effect of a Mediterranean-style diet supplemented with nuts or virgin olive oil on erythrocyte membrane properties in 36 hypertensive participants after 1 year of intervention [59]. 
Erythrocyte membrane lipid composition, structural properties of reconstituted erythrocyte membranes, and serum concentrations of inflammatory markers were reported. The membrane cholesterol content decreased, whereas that of phospholipids increased in all of the dietary groups; the diminishing cholesterol:phospholipid ratio could be associated with an increase in the membrane fluidity. Moreover, reconstituted membranes from the nuts and virgin olive oil groups showed a higher propensity to form a nonlamellar inverted hexagonal phase structure that was related to an increase in phosphatidylethanolamine lipid class. It is possible that the Mediterranean-style diet affects the lipid metabolism that is altered in hypertensive patients, influencing the structural membrane properties. The erythrocyte membrane modulation described provides insight in the structural bases underlying the beneficial effect of a Mediterranean-style diet in hypertensive subjects.

The total fat intake in Mediterranean populations may be about $40 \%$ due to olive oil intake which is higher than in other populations who consume animal fat and vegetable seed oils. Increased olive oil consumption is implicated in a reduction in cardiovascular disease, rheumatoid arthritis, and, to a lesser extent, a variety of cancers. Olive oil intake also has been shown to modulate immune function, particularly the inflammatory processes associated with the immune system [60]. Olive oil has potential antioxidant and antiinflammatory properties which may explain its beneficial effects on disease risk, since oxidative and inflammatory stresses appear to be underlying factors in the etiology of CVDs and other chronic diseases in man. The antioxidant effects of olive oil are probably due to a combination of its high oleic acid content (low oxidation potential compared with linoleic acid) and its content of a variety of plant antioxidants, particularly oleuropein, hydroxytyrosol, and tyrosol. The high oleic acid content and a proportionate reduction in w-6 fatty acid intake may allow a greater conversion of alpha-linolenic acid (18:3n-3) to longer-chain n-3 PUFA, which have characteristic health benefits by enhancing the incorporation of w-3 fatty acids in to cell membrane phospholipids.

\section{DIET AND ADIPOCYTE SIGNALING}

Increased consumption of refined starches and saturated fat, w- 6 fat and trans fat are known to enhance obesity and systemic inflammation in the tissues whereas increased intake of w-3 fatty acids, fruits, vegetables and nuts can decrease these risk factors. Obese hypertrophic adipocytes and stromal cells within adipose tissue directly augment systemic inflammation [61]. This increase in diet- and lifestyleinduced systemic inflammation mediates multiple pathogenic mechanisms in the possible associations between obesity, cardiovascular pathology, and the comorbidities such as dyslipidemia, type 2 diabetes mellitus, hypertension, and the metabolic syndrome.

Rapidly absorbed proinflammatory foods may activate the nuclear factor $\kappa \mathrm{B}(\mathrm{NF}-\kappa \mathrm{B})$ signaling cascade and induce the secretion of antibacterial peptides and other defense mechanisms as well as proinflammatory transcription factors; AP 1 and EGR 1. Since the discovery of innate immunity and the acute phase response in humans such as during acute hyperglycemia, acute myocardial infarction and stroke, it has been thought that these functions were primarily the domain of the liver. However, recent evidence indicates that fat storage in the adipose tissue provides the ability to fulfill some aspects of innate immunity in adipocytes. Apart from adipocytes, adipose tissue contains fibroblasts, preadipocytes, tissue resident macrophages, and vascular constituents. Adipocytes possess significant intrinsic inflammatory properties, similar to macrophages. The adipocytes are highly sensitive to infectious disease agents and cytokinemediated inflammatory signals. It is possible that adipocytes are sensitive to the effects of TNF- $\alpha$, which, through its TNF receptors, stimulates NF- $\mathrm{KB}$, extracellular signal-regulated kinase, and mitogen-activated protein kinases PI-3 kinase and jun-N-terminal kinase cascades which are possibly increased on increased consumption of a proinflammatory Western diet [62].

Adipocyte expresses a host of receptors, enabling it to sense the presence of pathogens and inflammation, and on stimulation of these receptors, it activates multiple inflammatory signal transduction cascades, and induces and secretes a number of potent inflammatory cytokines and acute phase reactants [62]. The mammalian toll-like lipopolysaccharide (LPS) receptor TLR4 is expressed in tissue and in vitro cultured adipocytes. When stimulated with endotoxin, these receptors activate $\mathrm{p} 65 / \mathrm{p} 50$ and p68/p52 NF- $\mathrm{kB}$ signal transduction pathways. In turn, these pathways induce the expression of inflammatory mediators such as interleukin-6 (IL-6), TNF- $\alpha$, and serum amyloid A3. In response to infectious and inflammatory signals, adipocytes have been shown to induce expression and secretion of several acute phase reactants and mediators of inflammation, including TNF- $\alpha$, plasminogen activator inhibitor-1 (PAI-1), IL-1 $\beta$, IL-6, IL-8, IL-10, and IL-15, leukemia inhibitory factor, hepatocyte growth factor, macrophage migration inhibitory factor, haptoglobin, complement factors $\mathrm{B}, \mathrm{D}, \mathrm{C} 3$, prostaglandin $\mathrm{E} 2$, and potential inflammatory modulators such as leptin, adiponectin, and resistin. Although many of these activities are restricted to autocrine and paracrine effects, some of these cytokines secreted from adipocytes and adipose-resident macrophages make significant contributions to systemic inflammation.

In 1993, it was discovered that TNF- $\alpha$ expression was upregulated in adipose tissue of obese mice [63]. The induction of inflammatory mRNA transcripts in adipose tissue can originate in either adipocytes or their surrounding resident macrophages, and adipocytes and resident macrophages not only contribute independently to the local adipose inflammatory output, they each synergistically stimulate inflammatory activity of the other. Heterotypic signaling experiments using cultured adipocyte conditioned media have demonstrated that the inflammatory signals secreted by unstimulated adipocytes induce a dramatic increase of IL- 6 and TNF- $\alpha$ secretion by otherwise unstimulated cultured macrophages in vitro. This autocrine and paracrine signaling becomes part of the adipocyte function.

These studies used high-fat diets rich in monounsaturated fatty acids. However, dietary PUFA seem to postpone diabetes development and have considerable impact on gene expression in a variety of tissues, including adipose tissue, 
where they regulate genes involved in adipocyte differentiation and lipid metabolism. In addition, PUFA, particularly those of the w-3 fatty acids that are found in marine fish oils, exert immunomodulatory effects, e.g. in inflammatory joint and bowel diseases. Immunomodulation by PUFA has been studied mainly in $\mathrm{T}$ lymphocytes and $\mathrm{T}$ cell-mediated diseases, but w-3 PUFA have been found to affect monocyte and macrophage functions as well. The effect of marine w-3 PUFA on white adipose tissue inflammation and gene expression was studied in $\mathrm{db} / \mathrm{db}$ mice on a high-fat diet. Todoric et al, [63] treated $\mathrm{db} / \mathrm{db}$ mice as well as lean nondiabetic mice $(\mathrm{db} /+)$ with either low-fat standard diet (LF) or high-fat diets rich in [1] saturated/monounsaturatedfatty acids (HF/S), [2] n-6 PUFA (HF/6) and [3] the latter including purified marine $n-3$ PUFA (HF/3). Many genes involved in inflammatory alterations were up regulated in $\mathrm{db} / \mathrm{db}$ mice on $\mathrm{HF} / \mathrm{S}$ compared with LF in parallel with phosphorylation of c-Jun N-terminal kinase(JNK). In parallel, adipose tissue infiltration with macrophageswas markedly enhanced by $\mathrm{HF} / \mathrm{S}$. When compared with HF/S, HF/6 showed only marginal effects on adipose tissue inflammation. However, inclusion of $\mathrm{w}-3$ PUFA in the $\operatorname{diet}(\mathrm{HF} / 3)$ completely prevented macrophage infiltration induced by high-fat diet and changes in inflammatory gene expression, also tending to reduce JNK phosphorylation $(\mathrm{p}<0.1)$ in diabetic mice despite unreduced bodyweight. Moreover, high-fat diets (HF/S, $\mathrm{HF} / 6$ ) down regulated expression and reduced serum concentrations of adiponectin, but this was not the case with w-3 PUFA. w-3 PUFA prevent adipose tissue inflammation induced by high-fat diet in obese diabetic mice, thereby dissecting obesity from adipose tissue inflammation. These data suggest that beneficial effects of w-3 PUFA on diabetes development could be mediated by their effect on adipose tissue inflammation. A recent study reported that one microRNA in particular, MIR168a, which is highly enriched in rice, was found to inhibit a protein that helps remove lowdensity lipoprotein (LDL) from the blood, suggesting that microRNAs can influence gene expression across kingdoms [64].

\section{EFFECT OF PALEOLITHIC STYLE DIET ON CORONARY ARTERY DISEASE}

There is additional evidence from other studies indicating the role of w-6/w-3 ratio of fatty acids in the pathogenesis of CVDs [65-70]. The physiological functioning of these tissues is determined by the nutrients present in the Paleolithic style diet which have protective effects and the Western dietary patterns that have adverse effects. There is clear evidence that dietary changes or $\mathrm{w}-3$ fatty acid supplementation and decrease in w- 6 fatty acid intake may induce a marked alteration in the $w-6 / w-3$ fatty acid ratio in the tissue. This alteration in the fatty acid ratio may be associated with the large reduction in risk observed in several studies. A value of w-6/w-3 ratio of 1-2:1 has been shown by Simopoulos to be the ratio in the traditional diet of Crete, where the concept of Mediterranean diet originated from [67].

Further studies indicate that a prudent dietary pattern, similar to a Mediterranean-style diet [31, 32, 71-74] may be protective against NCDs; cardiovascular diseases [33, 34, 75], hypertension [76, 77], CAD and stroke [78], metabolic syndrome [25, 26], myocardial infarction [34, 79-81], type 2 diabetes, osteoporosis and degenerative diseases of the brain. Further studies showed that a fruit and vegetable enriched diet can protect against myocardial infarction and modulate microvascular function [76]. The beneficial effects of the Paleolithic prudent dietary pattern may be because of low w6 fatty acids and high content of ALA, antioxidants, flavonoids, vitamins and carotenoids present in the diet. Omega-3 fatty acids, such as ALA, is rich in mustard oil, walnuts, green leaves, whole grains, and seeds and EPA and DHA are rich in fish and fish oil and can protect against ventricular premature beats and myocardial infarction [34,82-84] . Randomized, controlled intervention trials [37, 40, 77, 85-86] also confirm that a Paleolithic style diet can cause significant decline in morbidity and mortality due to cardiovascular events which may be because of the ALA present in such a $\operatorname{diet}[36,39]$.

These findings need re-emphasis because of new research evidence showing multiple functions of Paleolithic style diet on cardiovascular functions and NCDs. Several of these studies were conducted when thrombolysis and angioplasty were not freely available for the treatment of acute coronary syndrome (ACS) [85, 86]. Therefore it is not possible to conduct such studies again to demonstrate the role of diet in the prevention of ACS, although the present authors [46, 87, 88] and many other agencies now advise increased intake of fruits and vegetables for the prevention of CVDs [89-91]. Diet can also provide beneficial or adverse effects by its influence on gut-brain-liver axis leading to increase or decline in CVDs $[29,39]$. These studies further emphasize that tissue is the main issue rather than associated risk factors of CVDs (q.v. also [20, 24, 48-51, 52 ]).

\section{EPIDEMIOLOGICAL STUDIES}

Epidemiological studies indicate that a prudent dietary pattern characterized by fruit, vegetable, legume and whole grain intake appears to be protective. The protective effects of prudent dietary patterns appear to be due to a low w- $6 / \mathrm{w}-3$ ratio of such diets because Western diet and South Asian diets have high w-6/w-3 ratio of 20 to 50 as shown in recent studies $(20,23,46-48,51]$. It is possible that w-3 fatty acids rich in Mediterranean diet, are known to inhibit and w-6 fatty acids rich in the Western diets, enhance tissue pathways resulting in inflammation in the tissues responsible for CVDs. These studies also indicate that CAD and all-cause mortality can be decreased without reduction in blood lipids and other traditional risk factors, which possibly may be due to alteration in tissues. The INTERHEART study, involving participants from 52 countries [81], examined the relationship between dietary patterns and risk of acute coronary syndrome (ACS). Consistent with previous studies in single within-population cohort studies, the authors found an inverse association between the prudent pattern score and risk of ACS and a significant positive association between the Western pattern score and increased risk of ACS. No association of Oriental diet with risk of ACS was reported. A dietary risk score based on 7 food items on the foodfrequency question-naire (meat, salty snacks, fried foods, fruits, green leafy vegetables, cooked vegetables, and other raw vegetables) was constructed by the authors. The investigators found that a higher score, indicating a poor diet, was strongly associated with ACS risk and the subjects in the 
highest quartile of the score had nearly a 2-fold increased risk, even after adjustment for established coronary risk factors. On the basis of an arbitrary cut point of the score (top 3 quartiles versus the bottom quartile), the investigators estimated that $30 \%$ of myocardial infarction (MI) could be explained by unhealthy diets worldwide. The INTERHEART study is the first large study to quantify eating patterns in all geographic regions of the world. It provides evidence that despite different food habits in various populations, reproducible patterns can be found in diverse regions of the world. These findings are important because there has been a concern that dietary patterns derived through a data-driven approach such as Principal Components Analysis may be highly unstable and non-reproducible because of very different eating habits in different populations.

In a largeprospective, observational study [75] involving 72,113 female nurses who were free of CAD, stroke, diabetes, and cancer, factor analysis identified 2 dietary patterns from data collected using serial food frequency questionnaires. One pattern, called prudent, was characterized by a high consumption of vegetables, fruit, legumes, fish, poultry, and whole grains. The other pattern, called Western, corresponded to a high consumption of red meat, processed meat, refined grains, French fries, sweets, and desserts. Individuals were classified by their level of adherence to both the prudent diet and the Western diet. After baseline data collection in 1984, follow-up lasted 18 years, during which time 6011 deaths occurred (3319 [52\%] as a result of cancer; 1154 (19\%) resulting from cardiovascular disease (CVD); and $1718(29 \%)$ resulting from other causes). There was a $17 \%$ lower risk of total mortality among those who were most adherent to the prudent diet (highest versus lowest quintile of adherence), a $28 \%$ lower risk of CVD mortality, and 30\% lower mortality from non-CVD, non-cancer causes. Cancer was not associated with the inverse prudent dietary pattern. A comparison of the highest and lowest quintiles of adherence showed that consumption of the Western diet was associated with increased total mortality (21\%), CVD mortality $(22 \%)$, cancer mortality $(16 \%)$, and mortality from nonCVD, non-cancer causes $(31 \%)$. Hence, except for cancer, risk relationships for the prudent and Western dietary patterns appear to be the inverse of each other: mortality thus was increased as adherence to the prudent diet decreased and adherence to the Western diet increased. In one crosssectional survey of 6940 subjects, above 25 years of age, fruit, vegetable and legume intakes were inversely associated with risk of pre-hypertension and hypertension in five Indian cities [77].

A meta-analysis of cohort studies, quantitatively assessed the relation between fruit and vegetable intake and incidence of CAD which reported relative risks (RRs) and corresponding $95 \%$ confidence interval (CI) of CAD with respect to frequency of fruit and vegetable intake [74]. A total of 278 459 subjects (9143 CAD events) were included, with a median follow-up of 11 years. The individuals who had less than 3 servings/day of fruit and vegetables, the pooled RR of CAD was 0.93 (95\% CI: $0.86-1.00, \mathrm{P}=0.06)$ while those with more than 5 servings/day, the RR was 0.83 (0.77-0.89, $\mathrm{P}=0.0001$ ). This meta-analysis of prospective cohort studies demonstrated that increased consumption of fruit and vegetables, less than 3 to more than 5 servings/day is related to a
$17 \%$ reduction, whereas increased intake to $3-5$ servings/day is associated with a smaller and borderline significant reduction in CAD risk. These results provide evidence supporting that 5 or more servings per day of fruit and vegetables, are needed to protect from CVD.

Dietary-patterning analysis has been increasingly used recently, as an alternative method to traditional singlenutrient analysis because it can assess cumulative effects of the overall nutrients in the diet. Habitual intake patterns are typically quantified by statistical methods such as Factor or Cluster Analysis or diet-quality indexes based on prevailing dietary recommendations or healthful traditional diets e.g., the Mediterranean diet [36, 40, 71], the Japanese diet [52] and the Indo-Mediterranean diet [37-47]. Principal Components Analysis is commonly used to define dietary patterns using food consumption information to identify common underlying dimensions (factors or patterns) of food intake. The method aggregates specific food items based on the degree to which these food items are correlated with each other. A summary score for each pattern is then derived and can be used to examine relationships between various eating patterns and outcomes of interest such as CAD, diabetes mellitus, stroke and other chronic diseases. Earlier validation studies found that 2 major patterns (the prudent and Western patterns) identified through Principal Components Analysis of food consumption data assessed by food frequency questionnaires were reproducible over time and correlated reasonably well with the patterns identified from diet records. The consistent association observed between the Western or unhealthy dietary pattern (high in animal products, salty snacks, refined starches and sugar and fried foods and low in fruits and vegetables) and ACS risk indifferent regions of the world from the INTERHEART study and other studies as well as in our study, provide consistent evidence of the adverse effects of globalization on human nutrition and chronic disease risk. However, this evidence is indirect because these studies did not specifically assess the impact of global trade and marketing on food consumption patterns across different countries [71-75, 77, 81, 92]. Despite this weakness, most recent studies suggest that the current trend of dietary convergence toward a typical Western diet characterized with high w-6/w-3 ratio of fatty acids, is likely to play a role in the globalization of obesity, CVD, diabetes and cancer.

\section{INTERVENTION TRIALS ON LOW W-6/W-3 FATTY ACID RATIO PALEOLITHIC STYLE DIET AND MORTALITY}

Cohort studies provide an association of diet with risk of CVDs and deaths. However, randomized, controlled intervention trials are necessary to provide a scientific proof that diet has a role in the prevention of CAD [36, 37, 39, 40]. Intervention trials, using the whole diet approach so far produced are also in line with this epidemiological evidence. The effect of Paleolithic style diet was examined in patients ( $\mathrm{n}=204$ intervention group, $\mathrm{n}=202$ control group) with acute coronary syndromes, which showed significant decline in total cardiac events as well as in total mortality after 6 weeks and the benefit continued after one year $[85,86]$. Further follow up for 2 years in this study [93] is different from the published work, because its emphasis is on the Paleolithic dietary patterns and ALA content of the diet to be responsi- 
ble for the significant greater survival in the intervention group compared to control group (Tables 6 and 7). Dietary patterns before entry to the study showed higher w-6/w-3 ratio of 32.5 in the diets of both the groups. Intervention group A was advised a Paleolithic style diet with w- $6 / \mathrm{w}-3$ fatty acid ratio of 4.3 compared to standard diet group with ratio of 20 (Tables 6 and 7). After a follow up of 2 years, total mortality was significantly declined in the Paleolithic style diet group compared to control group (Fig. 1) [93]. The mortality was lowest among subjects with w- $6 / \mathrm{w}-3$ ratio of less than 10 which showed graded increase with increase in the fatty acid ratio in both the groups (Figs. 1 and 2.).

In the Lyon Diet Heart Study [36, 49], 605 patients who had a myocardial infarction were randomly assigned to a 'Mediterranean-style' diet or a control diet resembling the American Heart Association Step I diet. The Mediterranean diet model supplied $30 \%$ of energy from fats and $<10 \%$ of energy from saturated fatty acids, whereas the intake of $18: 3$ (w-3) (ALA) provided $>0.6 \%$ of energy. After a mean follow-up of 27 months, the risk of new acute myocardial infarction and episodes of unstable angina was reduced by $70 \%$ by the Mediterranean diet [36]. Moreover, total mortality was also reduced by 70\%. Long-term follow up for 4 years also showed that the beneficial effects of diet were continued [49].
Singh et al. [37], tested an 'Indo-Mediterranean diet' in 1000 patients in India, with existing coronary disease or at high risk for coronary disease. Half of the patients $(n=499$ vs. 501) were administered a diet rich in fruits, vegetables, whole grains, walnuts, mustard and soy bean oil as a source for w-3 fat and the rest, 501 patients were advised to take prudent diet advised by the National Cholesterol Education Program Step 1 diet in 1988 [89]. At the end of 2 year follow up, the Paleolithic style diet group consumed significantly more fruits, vegetables and legumes than did the control group (537 \pm 127 vs. $231 \pm 19 \mathrm{~g} /$ day, $\mathrm{p}<0.001)$ as well as more mustard and soy bean oil $(31 \pm 6.5$ vs. $15.2 \pm 5.5 \mathrm{~g} /$ day $)$. The mean intake of ALA was over two fold greater in the Paleolithic style diet group compared to control group. (1.8 \pm 0.4 vs. $0.8 \pm 0.2 \mathrm{~g} / \mathrm{day}, \mathrm{p}<0.001)$. The $\mathrm{w}-6 / \mathrm{w}-3$ ratio of fatty acids was slightly higher at baseline in the intervention group than in the control group ( $39 \pm 12$ vs. $34 \pm 10)$ yet both these values are extremely high, reflecting a diet with a very high w-6 content yet low w-3 [47]. At the end of two years follow up, this ratio showed a marked decline in the intervention group, which was greater than that observed in the control group consuming control diet $(9.1 \pm 12$ vs. $21 \pm 10, \mathrm{p}<0.001)$. The study end points were; significant decline in the total cardiac events, sudden cardiac death and non-fatal infarction in the intervention group compared to the control group (Table 8).

Table 6. Effect of w-3 Fatty Acid Rich Paleolithic Style Diet in Patients with Acute Myocardial Infarction

\begin{tabular}{|c|c|c|c|c|}
\hline Foods and nutrients & \multicolumn{2}{|c|}{ Paleolithic style diet group $(n=204)$} & \multicolumn{2}{|c|}{ Standard diet group ( $n=202)$} \\
\hline Potato, radish, & $60.5(6.8)$ & $115(12.7) * *$ & $72.0(12.5)$ & $155.6(32.5)$ \\
\hline Legumes and pulses (g. Day-1) & $80.5(6.6) * *$ & $95.0(8.9) * *$ & $52.5(4.6)$ & $45.6(5.6)$ \\
\hline Fish (g. Day-1) & $52.5(6.5) * *$ & $22.4(4.1) * *$ & $20.2(3.1)$ & $10.5(3.5)$ \\
\hline Chicken (g. Day-1) & - & $10.2(3.2)^{*}$ & $76.2(6.5)$ & $66.5(10.5)$ \\
\hline Mustard or soybean oil & $18.4(3.9)^{*}$ & $31.5(5.5) * *$ & $10.5(2.3)$ & $6.8(2.8)$ \\
\hline Butter or clarified butter (g. Day-1) & $2.5(0.6) * *$ & $3.3(0.71)^{*}$ & $10.5(2.6)$ & $12.6(3.5)$ \\
\hline Bread, biscuits (g. Day-1) & $10.6(2.2)^{*}$ & $25.5(6.2) * *$ & $230.6(20.1)$ & $212.2(18.1)$ \\
\hline Rice and wheat cereals (g. Day-1) & $25.6(2.4)$ & $30.6(5.5)$ & $30.2(3.1)$ & $35.6(4.8)$ \\
\hline Honey or raisins (g. Day-1) & $2.6(0.8)$ & $5.5(1.2)$ & - & - \\
\hline Sugar (g. Day-1) & $16.4(3.7)^{*}$ & $12.6(3.4)^{*}$ & $25.5(5.4)$ & $30.5(7.6)$ \\
\hline - & - & - & - & - \\
\hline Total Adherence score (\%) & $65.2(17.2)$ & $63.9(14.8)$ & $123.0(30.0)$ & $71.0(30.0)$ \\
\hline Total foods, & $1027(232)$ & $1184.6(254)$ & $983.4(213)$ & $862(204)$ \\
\hline
\end{tabular}

$\mathrm{P}$ values for mean (standard deviation) were obtained by comparison of intervention and control groups after 1 week and after 1 year. ${ }^{*}=\mathrm{P}<0.05,{ }^{* *} \mathrm{P}<0.01$, Singh et al. [77] their reference 40. 
Table 7. Fatty Acid Consumption in the Paleolithic Style Diet Group and Standard Diet Group

\begin{tabular}{|c|c|c|c|c|c|}
\hline \multirow[b]{2}{*}{ Fatty acid KJ/day } & \multirow{2}{*}{$\begin{array}{c}\text { Before entry } \\
\text { All patients }(n=406)\end{array}$} & \multicolumn{2}{|c|}{ At entry } & \multicolumn{2}{|c|}{ After one year } \\
\hline & & Paleolithic $(n=204)$ & Standard $(n=202)$ & Paleolithic $(n=204)$ & Standard (n-202) \\
\hline Saturated & $10.0(0.39)$ & $7.0(0.22)$ & $10.0(0.38)$ & $7.2(0.24)$ & $10.8(0.36)$ \\
\hline Monounsaturated & $9.3(0.38)$ & $9.5(0.37)$ & $7.6(0.26)$ & $8.0(0.35)$ & $10.2(0.32)$ \\
\hline Polyunsaturated & $6.7(0.30)$ & $8.1(0.44)$ & $6.5(0.39)$ & $8.6(0.39)$ & $7.0(0.26)$ \\
\hline $\mathrm{W}-6$ & $6.5(0.29)$ & $6.3(0.28)$ & $6.3(0.29)$ & $7.0(0.36)$ & $6.2(0.24)$ \\
\hline $\mathrm{W}-3$ & $0.2(0.07)$ & $1.8(0.13)^{* *}$ & $0.2(0.082)$ & $1.6(0.12)^{* *}$ & $0.3(0.083)$ \\
\hline $\mathrm{W}-6 / \mathrm{W}-3$ ratio & $32.5(3.3) * *$ & $3.5(0.76) * *$ & $31.5(2.4)$ & $4.4(0.56)^{* *}$ & $20.6(2.1)$ \\
\hline Main dietary oil & Pea nut & Mustard & Sunflower & Mustard & Sunflower \\
\hline
\end{tabular}

Values are mean \pm Standard deviation $* *=\mathrm{p}<0.01$, Singh et al [77], their reference [40].

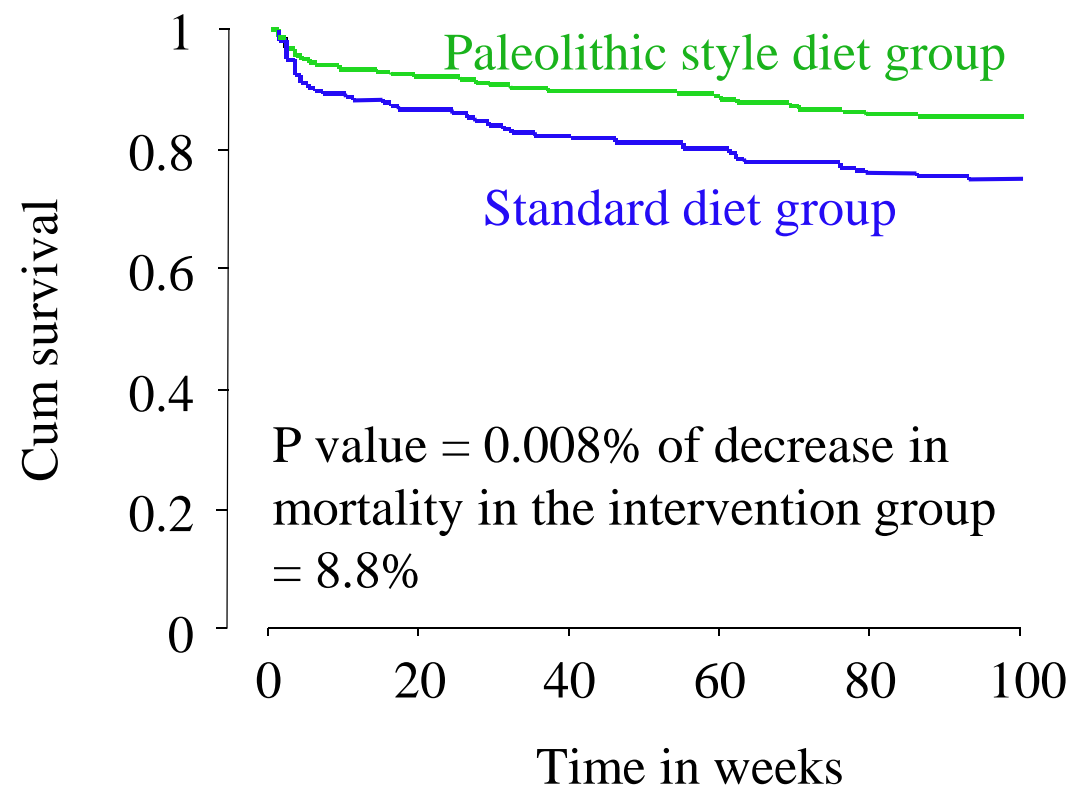

Fig. (1). Kaplan Meier survival curve: proportions of deaths after 2 years. Singh et al [77].

Esposito et al. [32], randomized 180 patients( 99 men, 81 women) with the metabolic syndrome to a Mediterranean style diet, characterized with whole grains, vegetables, fruits, nuts and olive oil vs. a cardiac-prudent diet with fat intake $<30 \%$. After a follow up of 2 years, subjects in the intervention diet showed greater weight loss, had lower C-reactive protein, and proinflammatory cytokine levels, had less insulin resistance, as well as lower total cholesterol and triglycerides and higher HDL cholesterol. The prevalence of metabolic syndrome was reduced to one half. The Japan Public Health Centre based study [52] showed that eating more w-3 fatty acids by increased intake of fish was associated with significant reduction in CVD and cardiac mortality. The diet and re-infarction trial [94] showed that modest intake of fish, 2 servings per week can cause significant decrease in total mortality and cardiovascular mortality. Since no benefit was observed in non-fatal infarction, the authors concluded that w-3 fatty acids may have prevented ventricular fibrillation by altering cardiomyocyte cell membrane phospholipids.
There is experimental evidence indicating that the very long chain w-3 fatty acids in fish oil and fatty fish have an important effect on the pathogenesis of arrhythmias in the setting of myocardial ischemia and reperfusion both in-vivo and invitro [95]. The role of w-3 fatty acids in decreasing inflammation has been established [96].

Cohort studies and intervention trials suggest that increased consumption of functional foods like fruits, green leafy vegetables, nuts and legumes decreases the risk of CVD morbidity and mortality (vide supra). Potentially protective content of these foods include ALA, EPA, DHA, folate, magnesium, calcium, potassium, fiber, vitamin E, carotenoids, arginine, taurine, cysteine, oleate and favorable lysine to arginine ratio and methionine to arginine ratios. These nutrients are important in the cardiomyocyte and arterial cell functions which are determinants of CVDs. The lysine to arginine ratio is being potentially involved in the atherogenesis and methionine to arginine ratio being important for endothelial function because arginine is the precursor 


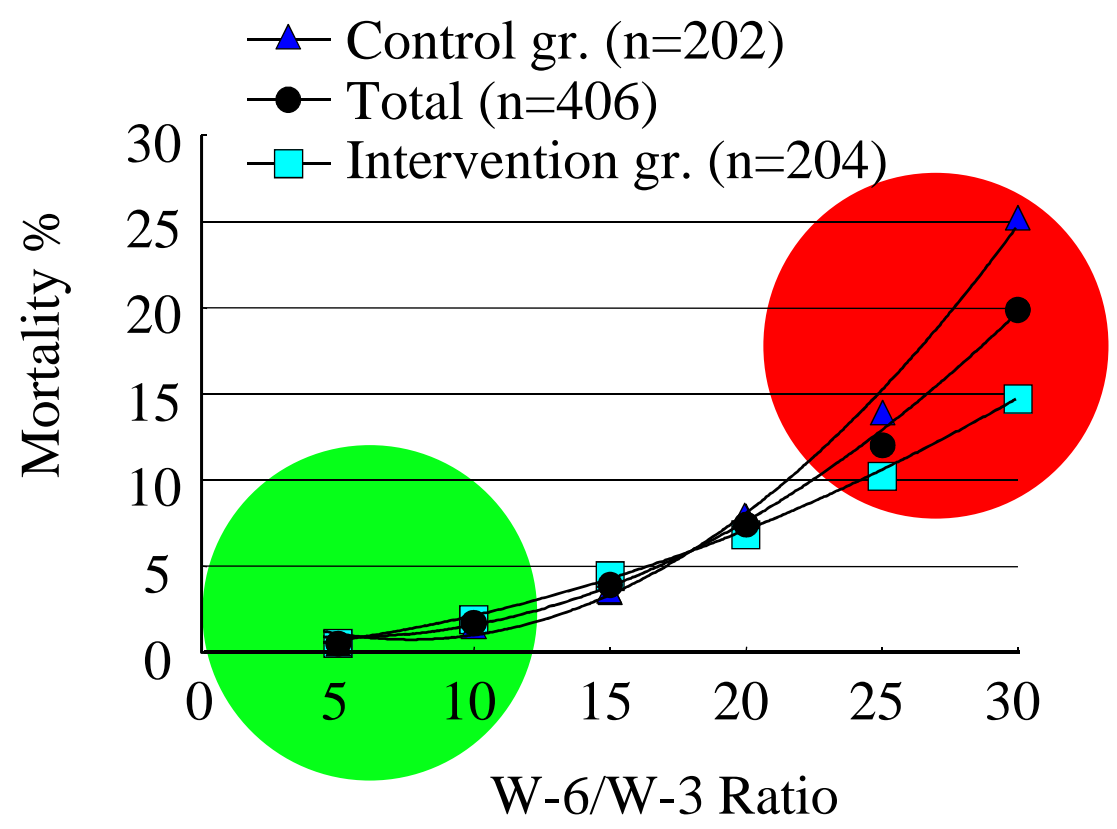

Fig. (2). Association of w-6/w-3 ratio of fatty acids with mortality in the intervention and control groups and among total subjects. Singh et al [77].

Table 8. Total Cardiovascular Events in the Paleolithic Style Diet and Control Group

\begin{tabular}{|l|l|l|}
\hline \multicolumn{1}{|c|}{ Data } & \multicolumn{1}{|c|}{ Indo-Mediterranean diet (n=499) } & \multicolumn{1}{c|}{ Standard Diet (n=501) } \\
\hline \hline Non fatal myocardial infarction & $21(4.2 \%)^{*}$ & $43(8.6 \%)$ \\
Fatal myocardial infarction & $12(2.4 \%)$ & $17(3.4 \%)$ \\
Sudden cardiac death & $6(1.2 \%)$ & $16(3.2 \%)$ \\
Total cardiac events & $39(7.8 \%)^{* *}$ & $76(15.2 \%)$ \\
Stroke & $7(1.4 \%)$ & $13(2.6 \%)$ \\
Stroke death & $2(0.4 \%)$ & $3(0.6 \%)$ \\
Total cardiovascular events & $48(9.6 \%)^{* *}$ & $92(18.3 \%)$ \\
Total deaths & $24(4.8 \%)$ & $38(8 \%)$ \\
\hline
\end{tabular}

Values are number $(\%), \quad *=\mathrm{P}<0.01,{ }^{* *}=\mathrm{P}<0.001$, Singh et al, [37] their references [35, 50].

of NO which protects the endothelium and methionine is the precursor of homocysteine that is known to cause endothelial damage. Folic acid is protective because it antagonizes the homocysteines. Calcium/ magnesium ratio indicating high magnesium is also protective to cardiomyocyte and endothelial cells. These findings indicate that it is the tissue which is the main issue in the pathogenesis and prevention of CVDs. If the tissue concentration of $\mathrm{w}-6 / \mathrm{w}-3$ ratio is $1: 1$ along with other nutrients in proper ratio, high LDL cholesterol (unoxidised) would possibly be neutral without any evidence of endothelial dysfunction. This concept has become more relevant because microRNA have been demonstrated in the blood and milk and alteration in the diet of grandparent can influence the health of grandchildren [64, 97]. Therefore, for prevention of CVDs, eat $400 \mathrm{~g} /$ day of fruits, vegetables and nuts and another $400 \mathrm{~g} /$ day of legumes and other whole grains along with $30-50 \mathrm{~g}$ of canola oil + olive oil to protect our tissues which is the major issue for conversion of Homo economicus to Homo modesties [98]. In this connection, variability in body functions should be foremost considered, as proposed by Wilson [99].

In brief, available evidence indicate that the biochemistry and biology of the tissues; especially myocardial and arterial tissue, appears to be of significant importance in the development of CAD and myocardial dysfunction. Dr Fabien De Meester, Dr D W Wilson and Dr Crwdord have been quite active in developing this concept.

\section{CONFLICTS OF INTEREST}

There are no declared conflicts of interest.

\section{ACKNOWLEDGEMENTS}

The International College of Nutrition, International College of Cardiology and the Tsim Tsoum Institute provided logistic support to write this article. 


\section{REFERENCES}

[1] Libby P, Rodker PM, Maseri A. Inflammation and atherosclerosis. Circulation 2002; 105: 1135-43.

[2] Li H, Cybulsky MI, Gimbrone MA Jr, et al. An atherogenic diet rapidly induces VCAM-1, a cytokine regulatable mononuclear leukocyte adhesion molecule, in rabbit endothelium. Arterioscler Thromb 1993; 13: 197-204.

[3] Cybulsky MI, Iiyama K, Li H, et al. A major role for VCAM-1, but not ICAM-1, in early atherosclerosis. J Clin Invest 2001; 107: 1255-62.

[4] Topper JN, Cai J, Falb D, et al. Identification of vascular endothelial genes differentially responsive to fluid mechanical stimuli: cyclooxygenase- 2 , manganese superoxide dismutase, and endothelial cell nitric oxide synthase are selectively up-regulated by steady laminar shear stress. Proc Natl Acad Sci USA 1996; 93: 10417-22.

[5] De Caterina R, Libby P, Peng HB, et al. Nitric oxide decreases cytokine induced endothelial activation: nitric oxide selectively reduces endothelial expression of adhesion molecules and proinflammatory cytokines. J Clin Invest 1995; 96: 60-8.

[6] Niskanen L, Laaksonen DE, Nyyssönen K, et al. Inflammation, abdominal obesity, and smoking as predictors of hypertension. Hypertension 2004; 44: 859-65.

[7] Festa A, D'Agostino R Jr, Howard G, Mykkänen L, Tracy RP, Haffner SM, Chronic subclinical inflammation as part of the Insulin Resistance Syndrome; The Insulin Resistance Atherosclerosis Study (IRAS). Circulation 2000; 102: 42-47.

[8] Baer DJ, Judd JT, Clevidence BA, Tracy RP. Dietary fatty acids affect plasma markers of inflammation in healthy men fed controlled diets: a randomized crossover study. Am J Clin Nutr 2004; 79: 969-73.

[9] Boots AW, Haenen GRMM, Bast A. Health effects of quercetin: from antioxidant to nutraceutical. Eur J Clin Pharmacol 2008; 585 (2-3): 325-37.

[10] Rodriguez-Leyva D, Pierce GN. The cardiac and haemostatic effects of dietary hempseed. Nutr Metab 2010; 7: 32.

[11] Mandel SO, Weinreb T, Amit WT, Youdim MBH. Cell signaling pathways in the neuroprotective actions of the green tea polyphenol (-)-epigallocatechin-3-gallate: implications for neurodegenerative diseases. J Neurochem 2004; 88(6); 1555-69.

[12] Du Y, Guo H, Lou H. Grape seed polyphenols protect cardiac cells from apoptosis via induction of endogenous antioxidant enzymes. J Agric Food Chem 2007; 55(5): 1695-701.

[13] Akhlaghi M, Bandy B. Dietary green tea extract increases phase 2 enzyme activities in protecting against myocardial ischemiareperfusion. Nutr Res 2010; 30(1): 32-9.

[14] Potenza MA, Marasciulo FL, Tarquinio M, et al. EGCG, a green tea polyphenol, improves endothelial function and insulin sensitivity, reduces blood pressure, and protects against myocardial I/R injury in SHR. Am J Physiol 2007; 292(5): E1378-87.

[15] Maddaford TG, Hurtado C, Sobrattee S, Czubryt MP, Pierce GN. A model of low-flow ischemia and reperfusion in single, beating adult cardiomyocytes. Am J Physiol 1999; 277: H788-98.

[16] Akhlaghi M, Bandy B. Preconditioning and acute effects of flavonoids in protecting cardiomyocytes from oxidative cell death. Oxid Med Cell Longev 2012; 2012: 9.

[17] Dupasquier CMC, Dibrov E, Kneesh AL, et al. Dietary flaxseed inhibits atherosclerosis in the LDL receptor-deficient mouse in part through antiproliferative and anti-inflammatory actions. Am J Physiol 2007; 293: H2394-402.

[18] Eaton SB, Konner M, Shostak M. Stone agers in the fast lane: chronic degenerative diseases in evolutionary perspective. AmerJ Med 1988; 84: 739-49.

[19] Eaton SB, Eaton SB III, Sinclair AJ, Cordain L, Mann NJ. Dietary intake of long chain polyunsaturated fatty acids during the Paleolithic period. World Rev Nutr Diet 1998; 83: 12-23.

[20] Simopoulos AP. Importance of the ratio of omega-6/omega-3 essential fatty acids: evolutionary aspects. World Rev Nutr Diet 2003; 92: 1-22.

[21] Simopoulos AP. Evolutionary aspects of the dietary omega6/omega-3 fatty acid ratio: medical implications. In Simopoulos AP, De Meester F (eds), A Balanced Omega-6/Omega-3 Fatty acid Ratio. Cholesterol and Coronary Heart Disease. World Rev Nutr Diet, Basel, Karger 2009; 100: 1-21.

[22] De Meester F. Wild-type land based food in health promotion and disease prevention. The Columbus Concept. Editors Fabien De
Meester, Ronald R Watson, Wild Type Food in Health Promotion and Disease Prevention. Humana Press, Totova, NJ: 2008. pp. 320.

[23] De Meester F. Progress in lipid nutrition. In: Simopoulos AP, De Meester F Eds, A Balanced Omega-6/Omega-3 Fatty acid Ratio. Cholesterol and Coronary Heart Disease. World Rev Nutr Diet. Basel, Karger. 2009; 100: 110-12.

[24] De Meester F. Progress in lipid nutrition: the Columbus concept addressing chronic diseases. World Rev Nutr Diet 2009; 100: 11021.

[25] Esposito K, Glugliano D. Diet and inflammation: a link to metabolic and cardiovascular diseases. Eur Heart J 2006; 27: 15-20.

[26] Katcher HI, Legro RS, Kunselman AR et al. The effects of whole grain- enriched hypocaloric diet on cardiovascular disease risk factors in men and women with metabolic syndrome. Am J Clin Nutr 2008; 87: 79-90.

[27] Fung TT, Malik V, Rexroad KM, Manson JE, Willett WC, Hu FB. Sweetened beverage consumption and risk of coronary heart in women. Am J Clin Nutr 2009; 89: 1037-42.

[28] Singh RB, DeMeester F, Mechirova V, Pella D, Otsuka K. Fatty acids in the causation and therapy of metabolic syndrome. In Wild type foods in health promotion and disease prevention, editors Fabien DeMeester and RR Watson, Humana Press, NJ 2008; pp. 263-84.

[29] Wang PY, Caspi L, Lam CK, et al. Upper intestinal lipids trigger a gut-brain-liver axis to regulate glucose production. Nature 2008; 452: 1012-6.

[30] Singh RB, De Meester F, Wilczynska A, Wilson DW, Hungin APS. The liver-pancreas and brain connection in the pathogenesis of obesity and diabetes mellitus. World Heart J 2010; 2: 319-26.

[31] Singh RB, Rastogi SS, Niaz MA, Ghosh S, Singh R. Effects of fat modified and fruits vegetable enriched diets on blood lipids in the Indian diet heart study. Am J Cardiol 1992; 69: 869-74.

[32] Esposito K, Marfella R, Ciotola M, et al. Effect of a Mediterranean-style diet on endothelial dysfunction and markers of vascular inflammation in the metabolic syndrome: a randomized trial. JAMA 2004; 292: 1440-6.

[33] Vogel RA. Eating, vascular biology, and atherosclerosis: a lot to chew on. Eur Heart J 2006; 27: 13-4.

[34] Singh RB, De Meester F, Pella D, Basu TK, Watson R. Globalization of dietary wild foods protect against cardiovascular disease and all cause mortalities? A Scientific statement from the International College of Cardiology, Columbus Paradigm Institute and the International College of Nutrition. Open Nutra J 2009; 2; 42-5.

[35] Singh RB, Reddy KK, Fedacko J, De Meester F, Wilczynska A, Wilson DW. Ancient Concepts of Nutrition and the Diet in Huntergatherers. Open Nutra J 2011; 4: 130-5.

[36] De Lorgeril M, Renaud S, Mamelle N, et al. Mediterranean alphalinolenic acid-rich diet in secondary prevention of coronary heart disease. Lancet 1994; 343(8911): 1454-9. Erratum in: Lancet 1995; 345(8951): 738.

[37] Singh RB, Dubnov G, Niaz MA, et al. Effect of an IndoMediterranean diet on progression of coronary disease in high risk patients: a randomized single blind trial. Lancet 2002; 360: 145561.

[38] Harper CR, Jacobson TA. Usefulness of omega-3 fatty acids and the prevention of coronary heart disease. Am J Cardiol 2005; 96: 1521-9.

[39] Gal D, Pella D, Singh RB. The effect of an alpha-linolenic acid rich diet on circadian rhythm of cardiac events. World Heart J 2008; 1: 49-56.

[40] Sofi F, Abbate R, Gensini GF, Casini A. Accruing evidence about benefits of adherence to Mediterranean diet on health: an updated systematic review with meta-analysis. Am J Clin Nutr 2010; 92(5): 1189-96.

[41] Keys A. Seven countries: A multivariate analysis of death and coronary heart disease. Cambridge, Mass. Harvard University Press. 1980.

[42] Singh RB, Niaz MA, Ghosh S, et al. Association of trans fatty acids (vegetable ghee), and clarified butter (Indian ghee) intake with higher risk of coronary artery disease in rural and urban populations with low fat consumption. Int J Cardiol 1996; 56: 289-98.

[43] Singh RB, Niaz MA, Beegom R, Wander GS, Thakur AS, Rissam HS. Body fat percent by bioelectrical impedence analysis and risk of coronary artery disease among urban men, with low rates of obe- 
sity: the Indian paradox. J Am Coll Nutr 1999; 18: 268-73.

[44] Singh RB, Beegom R, Verma SP, et al. Association of dietary factors and other coronary risk factors with social class in women in five Indian cities. Asia Pac J Clin Nutr 2000; 9: 298-302.

[45] Aratti P, Peluso G, Nicolai R, Calvani M. Polyunsaturated fatty acids: biochemical, nutritional and epigenetic properties. J Am Coll Nutr 2004; 23: 281-302.

[46] Singh RB, Moshiri M, De Meester F, Juneja L, Muthusamy V, Manoharan S. The evolution of low w-6/w-3 ratio dietary pattern and risk of cardiovascular diseases and diabetes. J Altern Med Res 2011; 3: 45-70.

[47] Pella D, Dubnov G, Singh RB, Sharma R, Berry EM, Manor O. Effects of an Indo-Mediterranean diet on the omega-6/omega-3 ratio in patients at high risk of coronary artery disease: The Indian paradox. In Simopoulos AP, Cleland LG, Karger, Eds. World Rev Nutr Diet 2003; 92: 74-80.

[48] Kartikey K, Singh G, Kidyore B, Somsunder YA, Howarth P. Association of dietary $\mathrm{W}-6 / \mathrm{W}-3$ fatty acid ratio and inflammation with risk of hip joint fracture. Open Nutra J 2010: 3: 1-5.

[49] De Lorgeril M, Salen P, Martin JL, Monjaud I, Delaye J, Mamelle N. Mediterranean diet, traditional risk factors and the rate of cardiovascular complications after myocardial infarction. Final report of the Lyon Diet Heart Study. Circulation 1999; 99: 779-85.

[50] Kang JS, Wang J, Wu I, et al. Fat-1 mice convert w-6 to w-3 fatty acids. Nature 2004; 427: 504.

[51] Eaton B. Evolution and cholesterol. World Rev Nutr Diet 2009; 100: 46-54.

[52] Iso H, Kobayashi M, Ishihara $J$, et al. Intake of fish and $\mathrm{n} 3$ fatty acids and risk of coronary heart disease among Japanese: The Japan Public Health Center-Based (JPHC) Study Cohort I. Circulation 2006; 113: 195-202.

[53] Corey E. The logic of chemical synthesis: multiple synthesis of complex carbogenic molecules. Nobel Lect 1990; 30: 686-708.

[54] Samuelsson B. From studies of biochemical mechanisms to novel biological mediators: prostaglandins, endoperoxides, throboxanes and leukotrienes. Nobel Lect 1982; 117-138.

[55] Samuelsson B. Leukotrienes, mediaters of immediate hypersensitivity reactions and inflammation. Science 1983; 220: 568-75.

[56] Devane WA, Hanus L, Breuer A, Per twee RG, Stevenson LA. Isolation and structure of brain constituent that binds to the cannabinoid receptors. Science 1992; 258: 1946-9.

[57] Wells BJ, Mainous AG, Everett CJ. Association between dietary arginine and C-reactive protein. Nutrition 2005; 21: 125-30.

[58] Prades J, Alemany R, Perona JS, et al. Effects of 2-hydroxyoleic acid on the structural properties of biological and model plasma membranes. Mol Membr Biol 2008; 25: 46-57.

[59] Barcelo F, Perona JS, Prades J, et al. Mediterranean style diet, effect on structural properties of the erythrocyte cell membrane of hypertensive patients. Hypertension 2009; 54: 1143-50.

[60] Wahle KW, Caruso D, Ochoa JJ, Quiles JL. Olive oil and modulation of cell signaling in disease prevention. Lipids 2004; 39: 122331

[61] Berg AH, Scherer PE. Adipose tissue inflammation and cardiovascular disease. Circ Res 2005; 96: 939-49.

[62] Ryden M, Dicker A, van Harmelen V, et al. Mapping of early signaling events in tumor necrosis factor-alpha-mediated lipolysis in human fat cells. J Biol Chem 2002; 277: 1085-91.

[63] Todoric J, Loffler M, Huber J, et al. Adipose tissue inflammation induced by high-fat diet in obese diabetic mice is prevented by $n-3$ polyunsaturated fatty acids. Diabetologia 2006; 49: 2109-19.

[64] Zhang L, Hou D, Chen X, et al. Exogenous plant MIR168a specifically targets mammalian LDLRAP1: evidence of cross-kingdom regulation by microRNA. Cell Res 2011; doi:10.1038/cr.2011.158, 2011.

[65] Endres S, Ghorbani R, Kelley VE. The effect of dietary supplementation with n-3 polyunsaturated fatty acids on the synthesis of interleukin-1 and tumor necrosis factor by mononuclear cells. N Engl J Med 1989; 320: 265-8.

[66] Kumar SG, Das UN, Kumar KV, Tan BKH, Das NP. Effects of n-6 and n-3 fatty acids on the proliferation and secretion of TNF and IL-2 by human lymphocytes in vitro. Nutr Res 1992; 12: 815-20.

[67] Simopoulos AP. Is Insulin Resistance Influenced by dietary linoleic acid and trans fatty acids? Free Radic Bio Med 1994; 17; 367-72.
[68] Simopoulos AP. Evolutionary aspects of diet, the omega-6/omega3 ratio and genetic variation: nutritional implications for chronic diseases. Biomed Pharmacol 2006; 60: 502-7.

[69] Simopoulos AP. The Importance of the omega-6/omega-3 fatty acid ratio in cardiovascular disease and other chronic diseases. Exp Biol Med 2008; 233: 674-88

[70] Appel LJ. Dietary patterns and longevity. Circulation 2008; 118: 214-5.

[71] Renaud S, de Lorgeril M, Delaye J, et al. Cretan Mediterranean diet for prevention of coronary heart disease. Am J Clin Nutr 1995; 61(6 Suppl): 1360S-7S.

[72] Trichopoulou A, Costacou T, Bamia C, Trichopoulos D. Adherence to a Mediterranean diet and survival in a Greek population. N Engl J Med 2003; 348: 2599-608.

[73] Knoops KTB, de Groot LC, Kromhout D, et al. Mediterranean diet lifestyle factors and 10-year mortality in elderly European men and women. The HALE project. JAMA 2004; 292: 1433-9.

[74] He FJ, Nowson CA, Lucas M, MacGregor GA. Increased consumption of fruit and vegetables is related to a reduced risk of coronary heart disease: meta-analysis of cohort studies. J Hum Hypertens 2007; 21: 717-28.

[75] Heidemann C, Schulze MB, Franco OH, et al. Dietary patterns and risk of mortality from cardiovascular disease, cancer, and all causes in a prospective cohort of women. Circulation 2008; 118: 230-7.

[76] McCall DO, McGartland CP, McKinley MC, et al. Dietary Intake of Fruits and Vegetables Improves Microvascular Function in Hypertensive Subjects in a Dose-Dependent Manner. Circulation 2009; 119: 2153-60.

[77] Singh RB, Fedacko J, Pella D, et al. Prevalence and risk factors of pre-hypertension and hypertension in five Indian cities. Acta Cardiol 2011; 66: 29-37.

[78] Fung TT, Chiuve SE, McCullough ML, Rexrode KM, Logroscino $\mathrm{G}, \mathrm{Hu}$ FB. Adherence to DASH- style diet and risk of coronary heart disease and stroke in women. Arch Intern Med 2008; 168: 713-20

[79] Gramenzi A, Gentile A, Fasoli M, Negri E, Parazzini F, La Vecchia C. Association between certain foods and risk of acute myocardial infarction in women. BMJ 1990; 300: 771-3.

[80] Singh RB, Pella D, DeMeester F. What to eat and chew in acute myocardial infarction. Eur Heart J 2006; 27: 1628-9.

[81] Iqbal R, Anand S, Ounpuu S, et al. Dietary patterns and the risk of acute myocardial infarction in 52 countries. Circulation 2008; 118 : 1929-37.

[82] Harris WS, Reid KJ, Sands SA, et al. Blood omega-3 and trans fatty acids in middle aged acute coronary syndrome patients. Am J Cardiol 2007; 99: 154-8.

[83] Campos H, Baylin A, Willett WC. Alpha-Linolenic acid and risk of nonfatal acute myocardial infarction. Circulation 2008; 118: 33945

[84] Smith PJ, Blumenthal JA, Babyak MA, et al. Association between n-3 fatty acid consumption and ventricular ectopy after myocardial infarction. Am J Clin Nutr 2009; 89: 1315-20.

[85] Singh RB, Rastogi SS, Verma R, Bolaki L, Singh R, Ghosh S. An Indian experiment with nutritional modulation in acute myocardial infarction. Am J Cardiol 1992; 69: 879-85.

[86] Singh RB, Rastogi SS, Verma R, et al. Randomized, controlled trial of cardioprotective diet in patients with acute myocardial infarction: results of one year follow up. BMJ 1992c; 304: 1015-9.

[87] Singh RB, Niaz MA, Agarwal P, Beegum R, Rastogi SS. Effect of antioxidant rich foods on plasma ascorbic acid, cardiac enzyme and lipid peroxide levels in patients hospitalized with acute myocardial infarction. J Am Diet Assoc 1995; 95: 775-80.

[88] Singh RB, Dharwadkar S, De Meester F, Juneja L, Pella D. Role of cardioprotective diet in acute coronary syndrome. Am Med J 2011b; 2: 98-103.

[89] Anon. National Cholesterol Education Program; Report of the Expert Panel on detection, evaluation, and treatment of high blood cholesterol in adults. Arch Intern Med 1988; 148: 36-69.

[90] Anon. World Health Organization; Diet, Nutrition and Prevention of Chronic Diseases. Geneva, WHO. 1990.

[91] Anon. US Department of Agriculture and US department of Health and Human Services.Revised dietary Guidelines for Americans. 3rd edition, Washington, Washington DC, US Department of Agriculture. 1991.

[92] $\mathrm{Hu}$ FB. Globalization of food patterns and cardiovascular disease risk. Circulation 2008; 118: 1913-4. 
[93] Singh RB, Fedacko J, Vargova V, Niaz MA, Rastogi SS, Ghosh S. Effect of low W-6/W-3 ratio fatty acid Paleolithic style diet in patients with acute coronary syndromes. A randomized, single blind, controlled trial. World Heart J 2012; 4: 71-84.

[94] Burr ML, Fehily AM, Gilbert JF. Effects of changes in fat, fish and fibre intakes on death and myocardial infarction: Diet and Reinfarction Trial (DART). Lancet ii 1989; 2(8666): 757-61.

[95] McLennan PL, Abeywardena MY, Charnock JS. Dietary fish oil prevents ventricular fibrillation following coronary occlusion and reperfusion. Am Heart J 1988; 16: 709-16.

[96] Yang Y, Lu N, Chen D, Meng L, Zheng Y, Hui R. Effects of n-3 PUFA supplementation on plasma soluble adhesion molecules: a meta-analysis of randomized controlled trials. Am J Clin Nutr 2012; 95(4): 972-80.

[97] Alam SE, Singh RB, Gupta S, et al Nutritional aspects of epigenetic inheritance. Can J Physiol Pharmacol 2012; 90: 989-94.

[98] Singh RB, Takahashi T, Nakaoka T, et al. Nutrition in transition from Homo sapiens to Homo economicus. Open Nutra J 2013; 6: 617.

[99] Wilson DW. Biological rhythms. In: Body Clock. Managing Your Body Rhythms for Better Health and Fitness. Hughes, M. London: Weidenfeld \& Nicholson 1989; pp. 74-77.

Received: May 09, 2013

Revised: May 22, 2013

Accepted: May 22, 2013

(C) Singh et al.; Licensee Bentham Open.

This is an open access article licensed under the terms of the Creative Commons Attribution Non-Commercial License (http://creativecommons.org/licenses/by-nc/3.0/) which permits unrestricted, non-commercial use, distribution and reproduction in any medium, provided the work is properly cited. 